\title{
A new family linked to the RP13 locus for autosomal dominant retinitis pigmentosa on distal $17 p$
}

Department of Molecular Genetics, Institute of Ophthalmology, Bath Street, London ECIV 9EL, UK

E E Tarttelin S S Bhattacharya C F Inglehearn

\section{Department of} Clinical

Ophthalmology,

Institute of

Ophthalmology,

London, UK

C Plant

A C Bird

CNRS URA 1922, Généthon, Evry, France

J Weissenbach

Correspondence to: Dr Inglehearn.

Received 21 October 1995 Revised version accepted for publication 31 January 1996
Emma E Tarttelin, Catherine Plant, Jean Weissenbach, Alan C Bird, Shomi S Bhattacharya, Chris F Inglehearn

\begin{abstract}
A form of autosomal dominant retinitis pigmentosa (ADRP) mapping to chromosome 17p has been reported in a single large South African family. We now report a new family with severe early onset ADRP which maps to $17 \mathrm{p}$. Linkage and haplotype analysis in this family places the ADRP locus in the $5 \mathrm{cM}$ interval between markers AFMc024za5 and D17S1845, confirming the data obtained in the South African family. The discovery of a second $17 p$ linked family may imply that this is one of the more common loci for dominant RP. In addition, the confirmation of an $R P$ diagnosis at this locus is of interest since loci for a dominant cone dystrophy and Leber's congenital amaurosis (LCA1) have recently been linked to the same markers. While the cone dystrophy locus may be allelic with RP, our data and that of Goliath et al show that distinct genes are responsible for dominant $R P$ and Leber's congenital amaurosis on chromosome $17 \mathrm{p}$. ( $(\mathcal{M}$ Med Genet 1996;33:518-520)
\end{abstract}

Key words: retinitis pigmentosa; retina; $17 \mathrm{p} 13$

Retinitis pigmentosa (RP) is the name given to a group of inherited retinal dystrophies char- acterised by photoreceptor atrophy and pigment deposition in the retinal periphery. Patients experience narrowing of vision (tunnel vision) and night blindness, often progressing to complete blindness in later life. RP can be inherited in $\mathrm{X}$ linked, autosomal dominant, and autosomal recessive forms, and is also found in syndromes with other phenotypic defects. ${ }^{1}$ Clinical heterogeneity is seen within each of these categories with respect to severity of disease and age of onset of symptoms ${ }^{23}$ and there is considerable genetic heterogeneity.

Approximately $25 \%$ of ADRP is caused by mutations in the rhodopsin gene, ${ }^{4-6}$ and another retinal gene, RDS/peripherin, causes the disease in about $5 \%$ of ADRP families. ${ }^{78} \mathrm{Six}$ as yet uncharacterised ADRP genes have been localised to the pericentric region of chromosomes $8,{ }^{9} 7 \mathrm{p},{ }^{10} 7 \mathrm{q},{ }^{11} 19 \mathrm{q},{ }^{12} 17 \mathrm{p},{ }^{13}$ and $17 \mathrm{q} .{ }^{14}$ Each of these linkages was described in single large families. The reported $\mathrm{ADRP}$ locus on chromosome $17 p$ was based on linkage of $17 p$ microsatellites to the disease in a large South African family of British ancestry. This locus has now been given the name RP13 (MIM 600059).

We have carried out linkage studies on a panel of ADRP families from the Moorfields Eye Hospital genetic register. In one of these, family RP1729, originating in South Cumbria
I
II

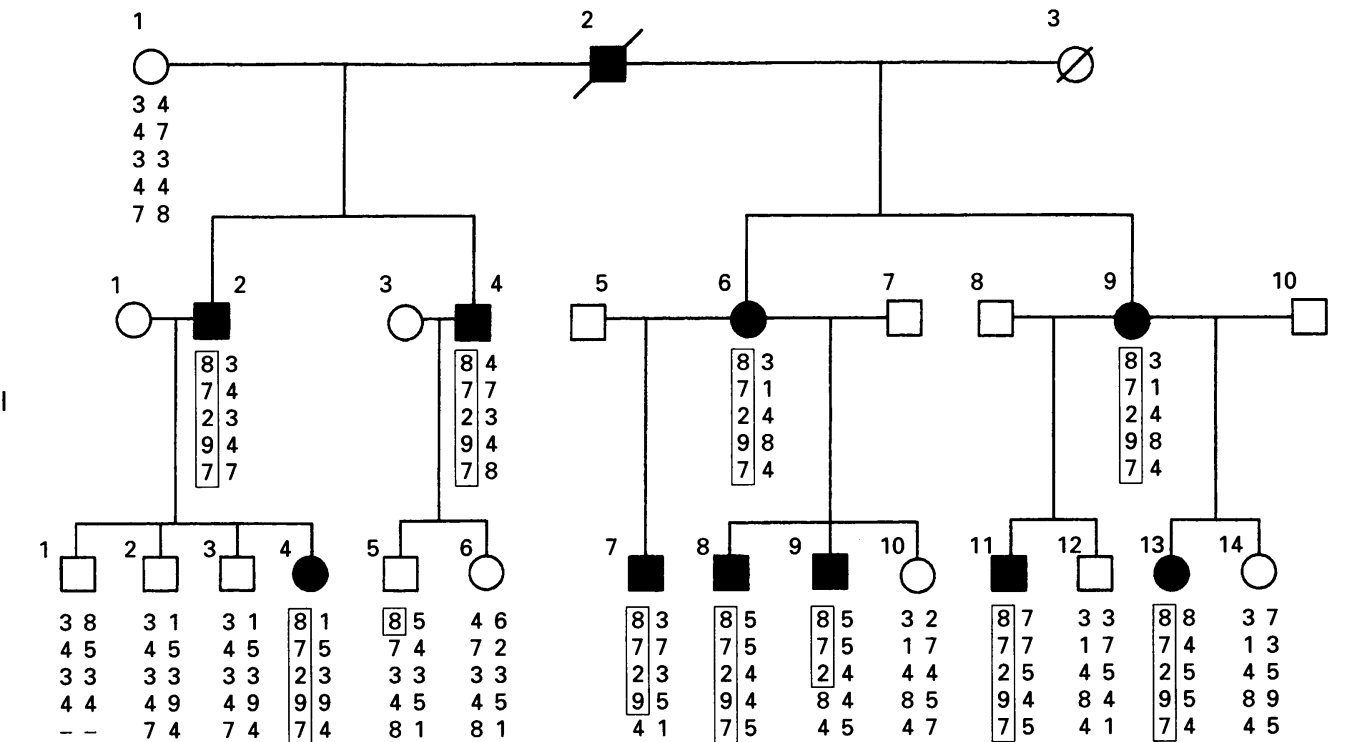

Figure 1 Haplotype analysis in pedigree RP1729. The five marker systems shown, from top to bottom, are: AFMc024za5, D17S1529, D17S831, D17S1845, and D17S796. The boxed haplotypes represent alleles associated with the disease chromosome. Critical recombination events can be seen in III.5, III. 7 , and III.9. 
Table 1 Details of new microsatellites used in this study

\begin{tabular}{|c|c|}
\hline Locus & Sequence \\
\hline AFMc024za5 & TGGATTCTGTAGTCCCAGG \\
\hline D17S1529 & TTGTTTCTATCCACGCAGGC \\
\hline D17S831 & $\begin{array}{l}\text { GATGGCTGTGCTTGCTGGTA } \\
\text { CGCCTTTCCTCATACTCCAG }\end{array}$ \\
\hline D17S1845 & $\begin{array}{l}\text { GCCAGACGGGACTTGAATTA } \\
\text { TGCCCATGCTGACATA } \\
\text { GACCTGACTAAAANACTCCA }\end{array}$ \\
\hline
\end{tabular}

in the north of England, the disease was found to map to the $17 \mathrm{p}$ locus. The phenotype in this family is one of classical RP with relatively early onset and a severe prognosis in comparison with other forms of ADRP. Genealogical investigation has failed to show any link between this and the original 17p linked family, and their places of origin are geographically widely separated. Critical recombination events within this family allow us to place the RP13 locus within a $5 \mathrm{cM}$ interval between the markers AFMc024za5 and D17S1845. This confirms the refinement data of Goliath et $a l,{ }^{15}$ which localise RP13 to a $3 \mathrm{cM}$ interval between the markers D17S1529 and D17S831.

\section{Materials and methods}

Affected members of pedigree RP1729 (fig 1) consistently report night blindness and visual field loss by 5 years of age, and are usually registered blind or partially sighted by 30 . Central vision is preserved until much later in the disease process, though some patients report blurred vision. One patient (III.4 in fig 1) was seen at the age of 10 and found to have $5^{\circ}$ visual fields with visual acuity of $6 / 18$ in both eyes. She was then examined again at 25 , with no significant evidence of progression in the interim period. Later complications in this form of RP include cystoid macular oedema and
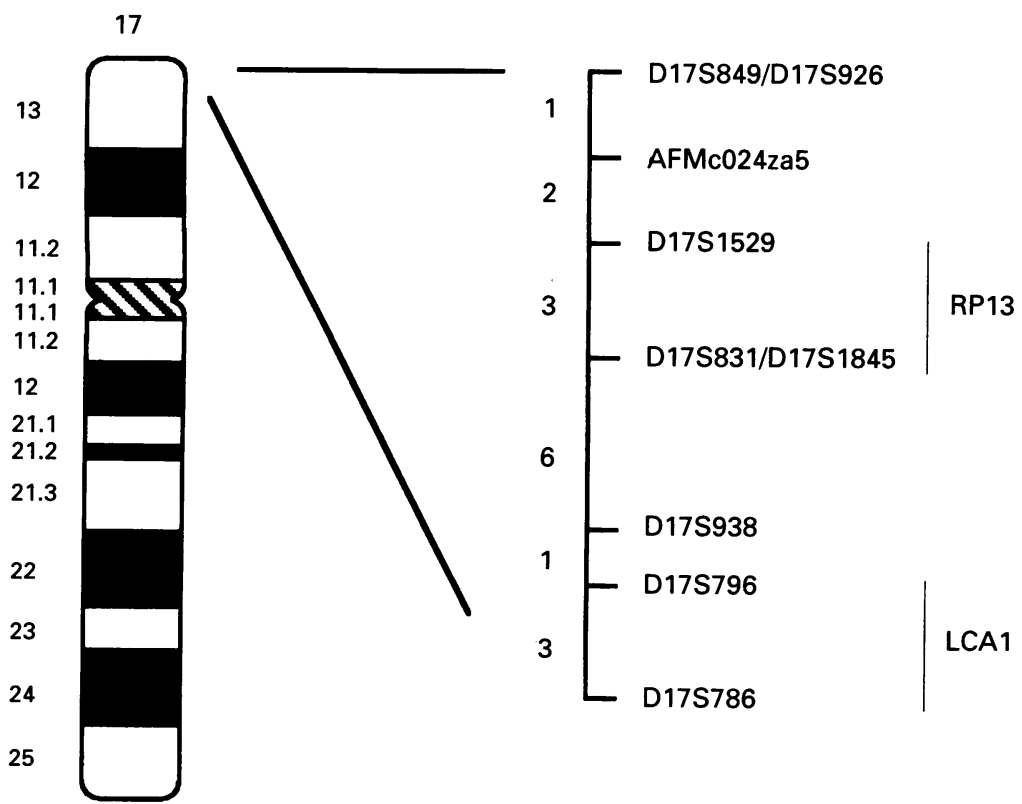

Figure 2 Schematic diagram indicating the genetic distances (in $c M$ ) between chromosome $17 p$ markers as described by Gyapay et al ${ }^{18}$ and Généthon (unpublished data). The localisation of RP13 (this study) and LCA $1^{19}$ are shown on the far right. cataract. Fundus examination in patients shows extensive bone spicule pigmentation in the midperiphery, attenuated blood vessels, and disc pallor, all classical symptoms of retinitis pigmentosa. Thus ADRP in this family is severe in comparison to disease resulting from mutations at other autosomal dominant loci, with no evidence of incomplete penetrance.

Patient DNA was prepared from peripheral blood lymphocytes by standard protocols. Microsatellite markers were typed by PCR using one radioactively labelled primer. Four new unpublished Généthon markers, AFMc024za5, D17S1529, D17S831, and D17S1845, which have been localised to the region, were used to refine the locus. The primer sequences are shown in table 1. Amplification was carried out using 30 cycles of $94^{\circ} \mathrm{C}$ for 30 seconds, $55^{\circ} \mathrm{C}$ for 30 seconds (except for marker D17S1845 which annealed optimally at $60^{\circ} \mathrm{C}$ ), and $72^{\circ} \mathrm{C}$ for 30 seconds. Products were separated on $6 \%$ acrylamide denaturing gels. Two point and multipoint lod scores were generated using the Linkage package version $5.1^{16}$ from data prepared by the LINKSYS data management package. ${ }^{17}$

\section{Results}

Five microsatellite markers were used to genotype 10 affected patients and eight unaffected sibs from family RP1729 (fig 1). The markers D17S849 and D17S796 from the second generation Généthon genome map ${ }^{18}$ were used to establish initial linkage to the $17 \mathrm{p}$ region. Four new unpublished Généthon markers, AFMc024za5, D17S1529, D17S831, and D17S1845, which have been localised to the region, were then used to refine the locus. The order and distance (in $\mathrm{cM}$ ) between these markers is shown in fig 2 .

The results of the two point linkage analysis between ADRP and each of the microsatellite markers are shown in table 2 . The highest two point lod score obtained was 4.8 at a recombination fraction of zero with marker D17S831. The marker D17S1529 also showed no recombination with the disease. Multipoint analysis with markers AFMc024za5, D17S1529, and D17S831, using marker order and intermarker distances as shown on the current Généthon map of the region (unpublished data), gave a maximum lod score of $5 \cdot 1$ at D17S831.

Haplotype analysis for the markers in the region is shown with the pedigree in fig 1 . Key recombination events were identified in subjects III. 5 and III. 9 which place the RP13 locus in a $5 \mathrm{cM}$ region between markers AFMc024za5 and D17S1845. The crossover seen in III. 5 is uninformative for D17S1529, so it remains possible that this crossover will prove to be proximal to D17S1529, further refining the locus. The RP13 region has recently been refined to a $3 \mathrm{cM}$ interval between markers D17S1529 and D17S831. ${ }^{15}$ Our results therefore confirm the localisation and refinement data on the 17p ADRP locus in a new linked family. 
Table 2 Two point lod scores (Z) between ADRP and markers on chromosome 17p

\begin{tabular}{|c|c|c|c|c|c|c|c|}
\hline \multirow[t]{2}{*}{$D N A$ marker } & \multicolumn{7}{|c|}{ Recombination fraction $(\theta)$} \\
\hline & 0.00 & $0 \cdot 10$ & $0 \cdot 20$ & $0 \cdot 30$ & $0 \cdot 40$ & $Z \max$ & $\theta \max$ \\
\hline \multicolumn{8}{|l|}{ tel } \\
\hline D17S849 & $-\infty$ & $1 \cdot 6$ & $1 \cdot 3$ & 0.9 & 0.5 & $1 \cdot 6$ & 0.086 \\
\hline AFMc024za5 & $-\infty$ & 2.5 & $2 \cdot 2$ & $1 \cdot 6$ & 0.8 & 2.53 & 0.081 \\
\hline D $17 S 1529$ & 3.5 & $2 \cdot 9$ & $2 \cdot 3$ & $1 \cdot 6$ & 0.8 & 3.5 & 0 \\
\hline D17S831 & $4 \cdot 8$ & $4 \cdot 0$ & $3 \cdot 1$ & $2 \cdot 2$ & $1 \cdot 1$ & $4 \cdot 8$ & 0 \\
\hline D17S1845 & $-\infty$ & $2 \cdot 2$ & 1.9 & $1 \cdot 3$ & 0.7 & $2 \cdot 3$ & 0.07 \\
\hline D17S796 & $-\infty$ & 0.5 & $0 \cdot 7$ & 0.5 & $0 \cdot 3$ & $0 \cdot 65$ & $0 \cdot 19$ \\
\hline
\end{tabular}

\section{Discussion}

We present data on an ADRP family RP1729, with a severe peripheral $R P$ phenotype, which is the second family mapping to the $17 \mathrm{p}$ locus. Mutations in rhodopsin are thought to account for around a quarter of ADRP, making rhodopsin-RP the most frequent form of the disease. However, it has been impossible to determine the frequencies of the six as yet uncharacterised loci, although a review of current published reports may give some idea of the frequencies. A second $19 q$ linked family has been reported, ${ }^{20}$ and a further three have been identified (AlMaghtheh et al, manuscript in preparation). Two further $7 \mathrm{q}$ linked families have also been reported. $^{2122}$ These observations suggest that rhodopsin and the loci on $17 \mathrm{p}, 7 \mathrm{q}$, and $19 \mathrm{q}$ are the more common ADRP loci, while those on $8 \mathrm{q}, 7 \mathrm{p}, 17 \mathrm{q}$, and $\mathrm{RDS} /$ peripherin are rarer.

The confirmation of an ADRP phenotype at this locus is significant since Syrquin et $a l^{23}$ have reported a locus for autosomal dominant cone degeneration linked to markers D17S513 and D17S796 in the same region. D17S796 is on the current Généthon map, but D17S513 is not placed on any of the available genome maps. Haplotype analysis in the RP13 linked family places this marker proximal to D17S1845 (data not shown). It is possible that the two disease phenotypes could be allelic, as is the case with ADRP and macular dystrophy mapping to chromosome $6 \mathrm{p} .{ }^{24}$ Mutations in the RDS/peripherin gene are responsible for both diseases despite wide variation in their phenotype.

Recently, a gene for Leber's congenital amaurosis (LCA), an autosomal recessive disease which causes congenital blindness, has also been mapped to $17 \mathrm{p} .{ }^{19}$ Significant linkage was shown between LCA1 and markers D17S831, D17S796, D17S1353, and D17S786, with a peak lod score of 7.21 at a recombination fraction of zero at D17S1353. Haplotype analysis places the LCA gene between the markers D17S796 and D17S786, as shown in fig 2 . The authors suggest that LCA1 may be allelic with RP13. However, our data and that of Goliath et $a l^{15}$ place the RP13 locus distal to D17S1845, proving that different genes are responsible for LCA1 and RP13.

By linkage analysis in RP1729 we have been able to confirm the earlier report of linkage to the RP13 locus, and localise RP13 to a $5 \mathrm{cM}$ interval between markers AFMc024za5 and D17S1845. Given the general tendency for genetic maps to expand at the telomeres relative to the physical map, this may correspond to a relatively small physical interval, so that a physical mapping and positional cloning approach could now be considered.

We thank the Wellcome Trust (grant numbers 035535/2/92/Z and $042375 / \mathrm{Z} / 94 / \mathrm{Z}$ ) for funding this research.

1 Botermans CHG. Primary pigmentary retinal degeneration and its association with neurological diseases. In: Vinken PJ, Bruyn GW, eds. Handbook of clinical neurology 13. PJ, Bruyn GW,

2 Massof RW, Finkelstein D. Two forms of autosomal dominant retinitis pigmentosa. Doc Ophthalmol 1981;51:28346

3 Lyness AL, Ernst W, Quinlan MP, et al. A clinical, psychophysical and electroretinographic survey of patients with autosomal dominant retinitis pigmentosa. $\mathrm{Br} \mathcal{F} \mathrm{Oph}$ thalmol 1985;69:326-39.

4 Dryja TP, Hahn LB, Cowley GS, McGee TL, Berson EL. Mutation spectrum of the rhodopsin gene among patients with autosomal dominant retinitis pigmentosa. Proc Nat Acad Sci USA 1991;88:9370-4.

5 Sung $\mathrm{CH}$, Davenport CM, Hennessey JC, et al. Rhodopsin mutations in autosomal dominant retinitis pigmentosa. Proc Natl Acad Sci USA 1991;88:6481-5.

6 Inglehearn CF, Keen TJ, Bashir R, et al. A complete screen for mutations of the rhodopsin gene in a panel of patients for mutations of the rhodopsin gene in a panel of patients
with autosomal dominant retinitis pigmentosa. Hum $\mathrm{Mol}$ Genet 1992;1:41-5.

7 Farrar GJ, Jordan SA, Kenna P, et al. Autosomal dominant retinitis pigmentosa: localisation of a disease gene (RP6) to the short arm of chromosome 6. Genomics 1991;11: $870-4$.

8 Kajiwara K, Mukai S, Travis GH, Berson EL, Dryja TP. Mutations in the human retinal degeneration slow gene (RDS) in autosomal dominant retinitis pigmentosa. Nature 1991;354:480-3.

9 Blanton SH, Heckenlively JR, Cottingham AW, et al. Linkage mapping of autosomal dominant retinitis pigmentosa (RP1) to the pericentric region of chromosome 8. Genomics 1991;11:857-69.

10 Inglehearn CF, Carter SA, Keen TJ, et al. A new locus for autosomal dominant retinitis pigmentosa on chromosome 7p. Nature Genet 1993;4:51-3.

11 Jordan SA, Farrar GJ, Kenna P, et al. Localisation of an autosomal dominant retinitis pigmentosa gene to chromosome 7q. Nature Genet 1993;4:54-7.

12 Al-Maghtheh $\mathrm{M}$, Inglehearn CF, Keen $\mathrm{TJ}$, et al. Identification of a sixth locus for autosomal dominant retinitis pigmentosa on chromosome 19. Hum Mol Genet 1994;3 $351-4$.

13 Greenberg J, Goliath R, Beighton P, Ramesar R. A new locus for autosomal dominant retinitis pigmentosa on the short arm of chromosome 17. Hum Mol Genet 1994;3 915-18.

14 Bardien S, Ebenezer N, Greenberg J, et al. An eighth locus for autosomal dominant retinitis pigmentosa is linked to chromosome 17q. Hum Mol Genet 1995;4:1459-62.

15 Goliath R, Shugart Y, Janssens P, et al. Fine localisation of the locus for autosomal dominant retinitis pigmentosa on the short arm of chromosome 17p. Am $\mathcal{F}$ Hum Genet 1995; 57:962-5.

16 Lathrop GM, Lalouel JM, Julier C, Ott J. Strategies for multipoint linkage analysis in humans. Proc Natl Acad Sci multipoint linkage analys

17 Attwood J, Bryant S. A computer programme to make analysis with LIPED and LINKAGE easier to perform and less prone to input errors. Ann Hum Genet 1988;52: 259.

18 Gyapay G, Morissette J, Vignal A, et al. The 1993-94 Généthon human genetic linkage map. Nature Genet 1994; 7:246-339.

19 Camuzat A, Dollfus H, Rozet JM, et al. A gene for Leber's congenital amaurosis maps to chromosome $17 \mathrm{p}$. Hum Mol Genet 1995;4:1447-52.

20 Nakazawa M, Xu S, Gal A, Tamai M. Phenotypic characteristics of Japanese family with autosomal dominant retinitis pigmentosa closely linked to comominan Invest Ophthalmol Vis Sci 1995;36(suppl):S891 (abstract 4092).

21 McGuire RE, Gannon AM, Sullivan LS, Rodriguez J-A Daiger SP. Evidence for a major gene (RP10) for autosomal dominant retinitis pigmentosa on chromosome 7q: linkage mapping in a second, unrelated family. Hum Genet linkage mapping

22 Millan JM, Martinez F, Vilela C, Beneyto M, Prieto F, Najera C. An autosomal dominant retinitis pigmentosa family with close linkage to D7S480 on 7q. Hum Genet 1995;96:216-18.

23 Syrquin MG, Gehrs K, Small KW. Mapping the gene responsible for autosomal dominant cone degeneration. Invest Ophthalmol Vis Sci 1995;36(Suppl):S4 (abstract 4902).

24 Wells J, Wroblewski J, Keen TJ, et al. Mutations in the human retinal degeneration slow (RDS) gene can cause either retinitis pigmentosa or macular dystrophy. Nature Genet 1992;3:213-18. 